\title{
Queuing Theory-A Tool For Optimizing Hospital Services
}

\author{
V.R.Girija ${ }^{1}$ and Prof.M.S.Bhat ${ }^{2}$ \\ ${ }^{1}$ Deccan School of Management, Department of Hospital Maagement, Hyderabad, India \\ Email: girijat4@yahoo.com \\ ${ }^{2}$ CVR College of Engineering, Department of Management Studies, Ibrahimpatan, R.R.District, A.P., India \\ Email: bhatms@rediffmail.com
}

\begin{abstract}
Allocation of scarce resources presents an increasing challenge to hospital administrators and health policy makers. In health care situations, we typically want to minimize cost or maximize quality or, more likely, some combination of these two. Application of queuing theory in hospital, attempts to improve the delivery of patient care services in the outpatient department as well as other departments. Calculation of Traffic intensity with a mean waiting time \& Service timings helps to understand the congestion and overcrowding in the system or to identify the service facilities which are idle, thus leading to optimization of resources.

This study analyzes the queuing characteristics in tertiary and secondary care government hospitals in twin cities of Hyderabad and Secunderabad. A sample of 200 patients were randomly selected and observed to understand their arrival and service patterns. Surprisingly both the hospitals had very less utilization rate $\mathbf{2 6 . 5 8 \%}$ in tertiary care $\& \mathbf{2 8 . 1 6 \%}$ in secondary care) and very high idle rate $\mathbf{( 7 3 \%}$ in tertiary care $\&$ $71 \%$ in secondary care). The results clearly show that the utilization rate is very small which needs attention by the policy makers to improve the efficiency of the system in both the government hospitals.
\end{abstract}

Index terms-queue, waiting line, optimization, arrival rate, service rate.

\section{INTRODUCTION}

Easy access is one of the fundamental demands placed on health services. Accessibility mainly in relation to waiting times is the aspect with which patients express greatest dissatisfaction. Although healthcare is usually delivered within a reasonable period, most people instinctively react to waiting times in a negative way.

In many countries, the critical importance of this issue prompted the rapid expansion of research on waiting times and access to health services. The main lines of research focus on theories to explain the causes of waiting times, analysis of the scope and consequences of waiting times, and evaluations of various initiatives aimed at correcting the problem.
One of the fundamental requirements on health services is good access to health care. "Good access" is defined as "the provision of care in relation to the needs of citizens, irrespective of their geographical, social or economic situation". Waiting times are one of the important aspects of access to health care. Waiting times and access to health services can be viewed as health policy issues. They can be related to the management and distribution of health care resources and the public's consumption of health services.

With the growing population \& changing life style, hospitals are getting crowded day by day. At the same time patients who are sick, hesitate to wait for longer periods in queue. Thus understanding the Queue behavior and optimizing on the Waiting time, Service cost as well as Idle resources is an important task that every hospital should achieve to tackle the needs of increased patient flow without making them wait for longer periods.

\section{LITERATURE REVIEW}

There has been some work on managing hospital waiting lists and allocating beds in a hospital to various services. One interesting aspect of health care waiting lists is the dynamic nature of the problem: as the queue increases, the reneging rate increases. People on the list look for services else where.

"Ref.[1]" analyzed and suggested the applications of Queuing theory in healthcare organizations around the world. He suggested that Queuing theory can be applied in health service capacity planning, emergency room arrivals, walk in patients in physician offices, outpatient clinics, outpatient surgeries in hospitals, hospital pharmacy and pharmacy stores, healthcare resource and infrastructure planning for disaster management and public health.

"Ref. [2]" reviews the use of Queuing theory in pharmacy applications with particular attention to 
improving customer satisfaction. "Ref. [3]" presents a brief history of the use of queuing theory in healthcare and gives the extensive list of the bibliography of the research works on queuing theory.

"Ref. [4]" discusses the application of Queuing in healthcare with respect to delays, utilization and number of servers. "Ref. [5]" analyses that increase in service capacity ,doesn't affect the queue much as patient arrival rate increases - as and when they feel that ,queue length is less.

\section{ObJeCtIVES Of The STUdY}

1. To study the waiting time distribution of patients in the Out Patient department of a Tertiary and Secondary care Government hospital.

2. To apply the Waiting Line model or Queuing Theory as a tool for optimizing hospital services.

\section{MATERIALS AND METHOdS}

\section{A. The data collection device}

Data is collected with the help of a questionnaire designed for finding patient expectations. Observation method is also used to find out the interarrival times of patients.

\section{B. The Sample}

A sample of 200 Out-patients (OP) each is taken from the secondary and tertiary government hospital. The period of the study is for 1 month. The survey is conducted in the general OP. There is an average daily general OP of 35 in the tertiary care and average daily general OP of 40 in the Secondary care. For 1 month the population is 1,050 patients in tertiary care \& 1200 in secondary care. Patients are selected randomly to find the inter-arrival timings and service timings.

\section{Data collection Process}

The data is collected through questionnaire method and observation. The questionnaire was prepared to find the patient expectations in the hospital which addressed some questions on waiting time of patients.

\section{Data Analysis and Results}

In most of the Queuing situations customer arrival is random i.e. the occurrence of an event is not influenced by the length of time that has elapsed since the occurrence of last event. Random interarrival and service times are described quantitatively in queuing models by the exponential distribution. The cumulative probability distribution function of Exponential distribution is given as in (1).

$$
F(t)=1-e^{-\lambda t}
$$

Where ' $\lambda$ ' is the arrival rate, ' $e$ ' $=2.71828$ and ' $t$ ' is time and $t>=0$. In the present study chi-square test of "Goodness of Fit" is used to test the following hypotheses.

\section{Hypotheses 1}

Ho: Inter-arrival time at Out Patient Department of tertiary care government hospital follows exponential distribution.

H1: Inter-arrival time at Out Patient Department of tertiary care government hospital does not follow exponential distribution.

\section{Hypotheses 2}

Ho: Inter-arrival time at Out Patient Department of secondary care government hospital follows exponential distribution.

H1: Inter-arrival time at Out Patient Department of secondary care government hospital does not follow exponential distribution.

\section{Hypotheses 3}

Ho: Service time at Out Patient Department of tertiary care government hospital follows exponential distribution.

H1: Service time at Out Patient Department of tertiary care government hospital does not follow exponential distribution.

\section{Hypotheses 4}

Ho: Service time at Out Patient Department of secondary care government hospital follows exponential distribution.

H1: Service time at Out Patient Department of secondary care government hospital does not follow exponential distribution.

The following tables show the inter-arrival times and service times of patients for both the hospitals.

TABLE-I

ARRIVAL TIME DISTRIBUTION FOR TERTIARY CARE GOVERNMENT HOSPITAL

\begin{tabular}{|c|c|c|c|c|c|c|}
\hline $\begin{array}{c}\text { Inter- } \\
\text { arrival } \\
\text { time } \\
\text { (minutes) }\end{array}$ & $5-10$ & $10-20$ & $20-30$ & $30-45$ & $45-60$ & $60-120$ \\
\hline $\begin{array}{c}\text { Observed } \\
\text { frequency ( } \\
\text { O) }\end{array}$ & 57 & 48 & 35 & 27 & 21 & 12 \\
\hline $\begin{array}{c}\text { Expected } \\
\text { Frequency } \\
\text { (E) }\end{array}$ & 49.97 & 37.48 & 35.83 & 29.2 & 20.77 & 20.38 \\
\hline
\end{tabular}

As per "Table I" the mean inter-arrival rate is 26.0875 minutes. The arrival rate is $(\lambda)$ is 2.3 patients per hour. The calculated value of $x^{2}$ is 7.572. The critical value of $\chi^{2}$ at 5 (6-1) degree of freedom for $\alpha$ $=5 \%$ level of significance is 11.070. Hence Ho (Inter-arrival time at Out Patient Department of tertiary care government hospital follows exponential 
distribution) in hypothesis 1 may be accepted, as calculated value is less than critical value.

TABLE-II

ARRIVAL TIME DISTRIBUTION FOR SECONDARY CARE GOVERNMENT HOSPITAL

\begin{tabular}{|c|c|c|c|c|c|c|}
\hline $\begin{array}{c}\text { Inter- } \\
\text { arrival } \\
\text { time } \\
\text { (minutes) }\end{array}$ & $5-10$ & $10-20$ & $20-30$ & $30-45$ & $45-60$ & $60-120$ \\
\hline $\begin{array}{c}\text { Observed } \\
\text { frequency } \\
\text { (O) }\end{array}$ & 68 & 42 & 37 & 30 & 10 & 13 \\
\hline $\begin{array}{c}\text { Expected } \\
\text { Frequency } \\
\text { (E) }\end{array}$ & 49.97 & 37.48 & 35.83 & 29.2 & 20.77 & 20.38 \\
\hline
\end{tabular}

As per "Table II" the mean inter-arrival rate is 24.425 minutes. The arrival rate is $(\lambda)$ is 2.45 patients per hour. The calculated value of $\chi^{2}$ is 10.989 . The critical value of $x^{2}$ at 5 (6-1) degree of freedom for $\alpha$ $=5 \%$ level of significance is 11.070. Hence Ho (Inter-arrival time at Out Patient Department of secondary care government hospital follows exponential distribution) in hypothesis 2 may be accepted, as calculated value is less than critical value.

TABLE- III

SERVICE TIME DistribUtion For TERTIARy CARE GOVERNMENT HOSPITAL

\begin{tabular}{|c|c|c|c|c|}
\hline $\begin{array}{c}\text { Service time } \\
\text { (minutes) }\end{array}$ & $0-5$ & $5-10$ & $10-15$ & $15-20$ \\
\hline $\begin{array}{c}\text { Observed } \\
\text { frequency (O) }\end{array}$ & 56 & 69 & 48 & 27 \\
\hline $\begin{array}{c}\text { Expected } \\
\text { Frequency (E) }\end{array}$ & 50.2 & 65.76 & 36.9 & 20.7 \\
\hline
\end{tabular}

As per "Table III" the mean service rate is 8.65 minutes. The service rate is $(\mu)$ is 6.936 patients per hour. The calculated value of $x^{2}$ is 6.086. The critical value of $x^{2}$ at $3(4-1)$ degree of freedom for $\alpha$ $=5 \%$ level of significance is 7.815. Hence Ho (Service time at Out Patient Department of tertiary care government hospital follows exponential distribution) in hypothesis 3 may be accepted, as calculated value is less than critical value.

TABLE-IV

SERVICE TIME Distribution For SECONDARY CARE GOVERNMENT HOSPITAL

\begin{tabular}{|c|c|c|c|c|}
\hline $\begin{array}{c}\text { Service time } \\
\text { (minutes) }\end{array}$ & $0-5$ & $5-10$ & $10-15$ & $15-20$ \\
\hline $\begin{array}{c}\text { Observed frequency ( } \\
\text { O) }\end{array}$ & 59 & 70 & 42 & 31 \\
\hline $\begin{array}{c}\text { Expected Frequency ( } \\
\text { E) }\end{array}$ & 49.95 & 65.59 & 36.92 & 20.78 \\
\hline
\end{tabular}

The mean service rate is 8.7 minutes. The service rate is $(\mu)$ is 6.896 patients per hour. The calculated value of $x^{2}$ is 7.6604. The critical value of $x^{2}$ at 3 (4-1) degree of freedom for $\alpha=5 \%$ level of significance is 7.815. Hence Ho (Service time at Out Patient Department of secondary care government hospital follows exponential distribution) in hypothesis 4 may be accepted, as calculated value is less than critical value.

From the above tables it is clear that inter-arrival timings and service timings in both the hospitals are following exponential distribution. With these findings a single server queuing model is applied to study the following queuing characteristics for both the hospitals. Utilization parameter or traffic intensity given by (2).

$$
\mathrm{P}=\lambda / \mu
$$

Idle rate or the probability that there are no customers in the system either in the queue or in the service given by (3).

$$
\text { Po }=1-p
$$

Length of the system or the average number of customers in the system or expected number of customers in the system given by (4).

$$
\mathrm{Ls}=\lambda /(\mu-\lambda)
$$

Length of the queue or the average number of customers in the queue or expected number of customers in the queue given (5).

$$
\mathrm{Lq}=\lambda^{2} /[\mu(\mu-\lambda)]
$$

Expected waiting time in the system or average waiting time in the system given (6).

$$
\mathrm{Ws}=1 /(\mu-\lambda)
$$

Expected waiting time in the queue or Average waiting time in the queue given by (7).

$$
\mathrm{Wq}=\lambda /[\mu(\mu-\lambda)]
$$

TABLE-V

QUEUING CHARACTERISTICS FOR TERTIARY AND SECONDARY CARE HOSPITAL

\begin{tabular}{|c|c|c|}
\hline Queue character & $\begin{array}{c}\text { Tertiary care } \\
\text { hospital ( minutes) }\end{array}$ & $\begin{array}{c}\text { Secondary care } \\
\text { hospital (minutes) }\end{array}$ \\
\hline$\lambda$ & 2.3 & 2.45 \\
\hline$\mu$ & 8.65 & 8.7 \\
\hline $\mathrm{P}$ & 0.2658 & 0.2816 \\
\hline $\mathrm{Po}$ & 0.73 & 0.71 \\
\hline $\mathrm{Ls}$ & 0.36 & 0.392 \\
\hline $\mathrm{Lq}$ & 0.096 & 0.11 \\
\hline $\mathrm{Ws}$ & 0.15 & 0.16 \\
\hline $\mathrm{Wq}$ & 1.688 & 1.76 \\
\hline
\end{tabular}


From the above table it is clear that both the hospitals are not differing much in their arrival and service timings. In both the hospitals $(73 \%$ in tertiary care $\& 71 \%$ in secondary care) the system is idle for a longer period of time. This clearly shows that for almost more than $70 \%$ of the time there are no customers either in the queue or in the system. Similarly the system is busy $(26.58 \%$ in tertiary care $\& 28.16 \%$ in secondary care) for less than $30 \%$ of the time. It means that the system has more capacity and can accommodate more patients in the given OP timings. The average number of customers either in the queue or in the system is not even one. Average waiting time in the queue is more for patients in both the hospitals (1.688 minutes in tertiary care and 1.76 minutes in secondary care) when compared to the average waiting time in the system $(0.15$ minutes in tertiary care \& 0.16 minutes in secondary care).

The results clearly show that the utilization rate is very small which needs attention by the policy makers. The resources can be better utilized to provide more care to the patients. May be opening the clinics in the evening and on government holidays may increase the patient flow and decrease the idle rate. Conducting medical camps often also increases patient flow.

\section{CONCLUSION}

Queuing theory helps to understand the different aspects of patients waiting in the queue as well as in the system. In both government hospitals the idle rate is more. This may be because of the patients more shifting for private healthcare. It is felt by patients that private hospitals provide better quality care when compared to government hospitals. Also insurance is helping patients to pay the high costs of private hospitals. At the same time private hospitals have more facilities, infrastructure and maintenance when compared to government hospitals.

The study can be extended to private hospitals to find the queuing characters in that hospital. The study was conducted only in the Outpatient department of both government hospitals. The study can be extended to find the queuing characteristics in emergency room arrivals, outpatient surgeries in hospitals, hospital pharmacy and disaster management as suggested by Reetu Mahendiratta ${ }^{1}$. Queuing theory application plays an important role in optimization of hospital services and increase the patient satisfaction by reducing the queue length or providing more servers in case of long queues. Similarly management can plan to optimally utilize the resources in case of large idle rates.

\section{REFERENCES}

[1] Reetu mahandiratta, "Applications of Queuing theory in Health Care," International Journal of computing and Business Research, vol. 2, issue 2, May 2011.

[2] R.A.Nosek, J.P.Wilson, "Queuing Theory and customer satisfaction: a review of terminology, trends and applications to pharmacy practice," Hospital Pharmacy 2001, PP 275-279.

[3] J.Preater "Queues in health", Healthcare Management science, Vol. 5, PP283, 2002.

[4] L.Green, "Queuing analysis in health care in patient flow: Reducing delay in health care delivery," Springer, NewYork, PP 281-308.

[5] D.J.Worthington, "Hospital waiting list management models," The journal of operation research society, Vol. 42, PP 833-843. 